\title{
Current trends and procedural outcomes in the era of rotational atherectomy expansion in Poland in the period 2014-2017 (based on the nationwide ORPKI registry)
}

\author{
Rafał Januszek ${ }^{1}$, Zbigniew Siudak², Krzysztof Reczuch ${ }^{3}$, Sławomir Dobrzycki ${ }^{4}$, Maciej Lesiak ${ }^{5}$, Jacek Legutko ${ }^{6}$ \\ Paweł Kleczyński ${ }^{1}$, Łukasz Rzeszutko ${ }^{1}$, Dariusz Dudek ${ }^{6}$, Stanisław Bartuś ${ }^{7}$ \\ ${ }^{1} 2^{\text {nd }}$ Department of Cardiology, University Hospital, Krakow, Poland \\ ${ }^{2}$ Department of Internal Medicine, Faculty of Medicine and Health Sciences, Jan Kochanowski University, Kielce, Poland \\ ${ }^{3}$ Department of Cardiology, $4^{\text {th }}$ Military Hospital, Wroclaw, Poland \\ ${ }^{4}$ Department of Invasive Cardiology, State Teaching Hospital, Medical University of Bialystok, Bialystok, Poland \\ ${ }^{5}$ First Department of Cardiology, Poznan University of Medical Sciences, Poznan, Poland \\ ${ }^{6}$ Department of Interventional Cardiology, Jagiellonian University Medical College, Krakow, Poland \\ ${ }^{7} 2^{\text {nd }}$ Department of Cardiology, Jagiellonian University Medical College, Krakow, Poland
}

Adv Interv Cardiol 2019; 15, 2 (56): 158-166

DOI: https://doi.org/10.5114/aic.2019.81387

\begin{abstract}
A bstract
Introduction: The availability of rotational atherectomy (RA) has recently increased in Poland, which was followed by an increase in the rate of RA procedures and catheterization laboratories performing RA.

Aim: To assess current trends regarding the rapid increase in the number of RA procedures and catheterization laboratories performing RA.

Material an methods: We analyzed patients treated with percutaneous coronary intervention (PCI) in the years 2014-2017 available in the nationwide ORPKI dataset. From the overall 431,467 patients treated with $\mathrm{PCI}$, we extracted 1,873 treated with RA. We analyzed the relationship between frequency of RA usage, its distribution between low and high volume centers and procedural outcomes, procedural-related complications and the $\mathrm{PCl}$ effectiveness expressed as the target vessel patency rate after $\mathrm{PCl}$.

Results: The number of RA procedures increased from 181 in 2014 (0.19\%) to 698 in 2017 (0.61\%), with an over two-fold increase in the number of catheterization laboratories performing RA from 25 (15.5\%) in 2014 to 55 (34.1\%) in 2017. Besides the fact that patient characteristics have changed in the most recent years, the rate of procedural success expressed as procedure-related complications remained stable in the 3 years 2015-2017 and was around 3\%, while the procedural effectiveness expressed as patent target coronary artery after $\mathrm{PCI}$ was stable and over $98 \%$ in all of the analyzed years.

Conclusions: Along with the increasing number of RA procedures and catheterization laboratories performing RA in Poland, the procedural effectiveness remained stable during an observational period of 4 years.
\end{abstract}

Key words: percutaneous coronary interventions, rotational atherectomy, periprocedural complications, procedural effectiveness.

Sum mary

The availability of rotational atherectomy (RA) has increased recently in Poland, which was followed by an increase in the rate of RA procedures and catheterization laboratories (CathLabs) performing. We observed an above threefold increase in the number of RA procedures from 181 in $2014(0.19 \%)$ to 698 in $2017(0.61 \%)$ and an above two fold increase in the number of CathLabs performing RA from 25 (15.5\%) in 2014 to 55 (34.1\%) in 2017. Apart from the increase the number of RA procedures and CathLabs performing RA, its procedural effectiveness remains at a stable level.

\section{Corresponding author:}

Stanisław Bartuś MD, PhD, 2 ${ }^{\text {nd }}$ Department of Cardiology, University Hospital, 17 Kopernika St, 31-501 Krakow, Poland, phone: +48 604112 699, e-mail: stanislaw.bartus@uj.edu.pl

Received: 2.10.2018, accepted: 16.12.2018. 


\section{Introduction}

The improvement of diagnostics and treatment methods in interventional cardiology among well-developed countries leads to an increase in the number of patients with more advanced atherosclerosis and disseminated calcified lesions as potential candidates for percutaneous coronary interventions ( $\mathrm{PCls}$ ) [1]. The $\mathrm{PCl}$ with rotational atherectomy (RA) could be an option for percutaneous treatment of complex and calcified coronary artery disease. Nowadays, due to an increase in overall experience and availability of RA, patients are more often being transferred from cardiac bypass surgery to $\mathrm{PCl}$ and treatment with $\mathrm{PCl}$, and RA could serve as a bridge between $\mathrm{PCl}$ and cardiac surgery in selected patients [2]. From a different point of view, it can be said that RA use could serve as a filter for patients with multivessel disease having severely calcified coronary artery stenoses, being potentially complex cases for cardiac surgery. Due to the fact that the reimbursement policy has changed in Poland in recent years, we can observe an increase in the rate of RA procedures and a gradual increase in the number of new catheterization laboratories all over the country [3]. It may be suspected that the currently visible decentralization of well-experienced centers in RA procedures could result in a change of procedure quality. The present European consensus on RA advises that optimal outcomes for the RA procedure are achieved by regular usage of this technology [4]. It is also suggested that it might be safer to consider transferring a patient to a high-volume center which is well experienced in this procedure [4]. Additionally, it is advised that potential rotablator operators could benefit from training at high-volume centers [4]. Moreover, in some countries, physicians intending to perform the RA procedure have to pass a certification course under supervision, which should be signed off by the RA training directorate [4]. However, the above-mentioned guidelines do not precisely indicate the number of annual RA procedures which have to be performed by a particular catheterization laboratory to be recognized as a high-volume center as well as the annual number of procedures to be performed by an experienced RA operator.

\section{Aim}

The aim of the present study was to assess current trends related to RA procedures in Poland at the time of its rapid growth and while the number of new low-volume centers is constantly increasing.

\section{Material and methods}

\section{Study population, design and definitions}

Data from all patients who underwent $\mathrm{PCl}$ in Poland between January 2014 and December 2017 were analyzed. Prospectively collected data on $\mathrm{PCl}$ practice in
Poland were obtained from the ORPKI Polish National dataset, which is coordinated nationwide by Jagiellonian University Medical College in cooperation with AISN PTK (Association of Cardiovascular Interventions, Polish Cardiac Society). Database characteristics and data collection methods have been previously published [3, 5-7]. Patients were categorized according to whether they were treated with RA or not over a 4-year period (2014-2017). Additionally, we presented the number of centers that can perform RA and centers with the highest RA procedure rate. Altogether, there are 162 centers in the database for these 4 years, but individual ones do not exist anymore, and some have just begun their activities. There are no centers in Poland not collecting data in the ORPKI database. All indices recorded in the ORPKI database are based on periprocedural data uploaded by the operator after each procedure. Therefore, they do not include all in-hospital complications, mainly those occurring after the procedure and until discharge from the hospital. Also, we did not collect follow-up data after discharge due to lack of patient IDs. At each center, the decision to perform the RA procedure was at the operators' discretion, according to current European recommendations [4]. All clinical decisions, such as vascular access, thrombectomy, and treatment with glycoprotein (GP) Ilb/Illa inhibitors or bivalirudin, were also the choice of the operator. The definition of periprocedural complications including death, perforation, dissection, allergic reaction, cerebral stroke, puncture-site bleeding, no-reflow, procedural-related myocardial infarction or cardiac arrest remained according to the operators' personal preferences and knowledge and with regard to current European definitions [8].

\section{Statistical analysis}

Continuous variables are presented as mean \pm standard deviation. Categorical variables are presented as numeric values and percentages. Continuous variables were compared using the Kruskal-Wallis ANOVA test, whereas in the case of categorical variables they were compared using the $\chi^{2}$ test. Statistical significance was accepted at a 0.05 level of probability. Statistical analyses were performed using the Statistica 10.0 software (Dell Software, Inc, Round Rock, TX, USA).

\section{Results}

General trends in RA frequency and the number of catheterization laboratories

The number of catheterization centers performing RA increased from 25 (15.5\%) in 2014 to 55 (34\%) in 2017, which was statistically significant $(p=0.001)$. Also, the number of RA procedures increased in successive years from $181(0.19 \%)$ in 2014 to 698 (0.61\%) in 2017. Despite the increase in the number of catheterization centers, the percentage of patients undergoing RA procedures in high-volume centers with an RA rate greater than 10 per 
year remained high and stable. Their value was $64.6 \%$, $85.6 \%, 83.6 \%$ and $83.7 \%$. When the rate of RA was greater than 20 per year, there was a slight tendency towards a decrease, and this totaled $51.4 \%, 54.1 \%, 34.1 \%$ and $46.8 \%$ in the successive years (from 2014 to 2017). The number of catheterization laboratories performing more than 20 RA procedures per year significantly increased in the studied period from 3 (12\%) to $8(22.2 \%), 5(11.1 \%)$ and $10(18.2 \%)$ in the successive years (from 2014 to 2017). This is presented in Table I and Figure 1.

Table I. Number of catheterization laboratories and patients in which rotational atherectomy angioplasties were performed in Poland between 2014-2017

\begin{tabular}{|c|c|c|c|c|c|}
\hline \multirow[t]{2}{*}{ Variable } & \multicolumn{4}{|c|}{ Years } & \multirow[t]{2}{*}{$P$-value } \\
\hline & 2014 & 2015 & 2016 & 2017 & \\
\hline Number of cath labs performing RA & $25(15.5)$ & $36(22.3)$ & $45(27.9)$ & $55(34.1)$ & 0.001 \\
\hline Number of cities performing RA & 17 & 22 & 28 & 36 & - \\
\hline Number of patients treated with $\mathrm{PCl}$ and RA & 181 & 458 & 536 & 698 & - \\
\hline Number of cath labs with > 10 RA/year & $5(20)$ & $19(52.8)$ & $24(53.3)$ & $28(51)$ & 0.03 \\
\hline Number of patients in cath labs with > 10 RA/year & $117(64.6)$ & $392(85.6)$ & $448(83.6)$ & $584(83.7)$ & $<0.001$ \\
\hline Number of cath labs with > 20 RA/year & $3(12)$ & $8(22.2)$ & $5(11.1)$ & $10(18.2)$ & 0.51 \\
\hline Number of patients in cath labs with > 20 RA/year & $93(51.4)$ & $248(54.1)$ & $183(34.1)$ & $327(46.8)$ & $<0.001$ \\
\hline Number of cath labs with $>30$ RA/year & $2(8)$ & $3(8.3)$ & $3(6.7)$ & $3(5.4)$ & 0.95 \\
\hline Number of patients in cath labs with > 30 RA/year & $71(39.2)$ & $107(23.4)$ & $133(24.8)$ & $166(23.8)$ & $<0.001$ \\
\hline Number of cath labs with > 50 RA/year & $0(0)$ & $1(2.8)$ & $1(2.2)$ & $2(3.6)$ & 0.81 \\
\hline Number of patients in cath labs with > 50 RA/year & $0(0)$ & $50(10.9)$ & $58(10.8)$ & $134(19.2)$ & $<0.001$ \\
\hline
\end{tabular}

cath lab-catheterization laboratory, $\mathrm{PCl}$ - percutaneous coronary intervention, RA - rotational atherectomy.

A

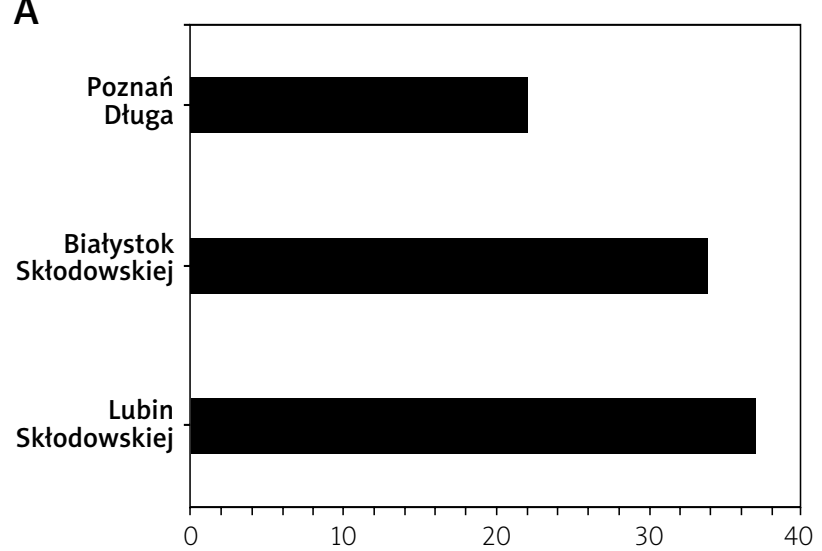

C

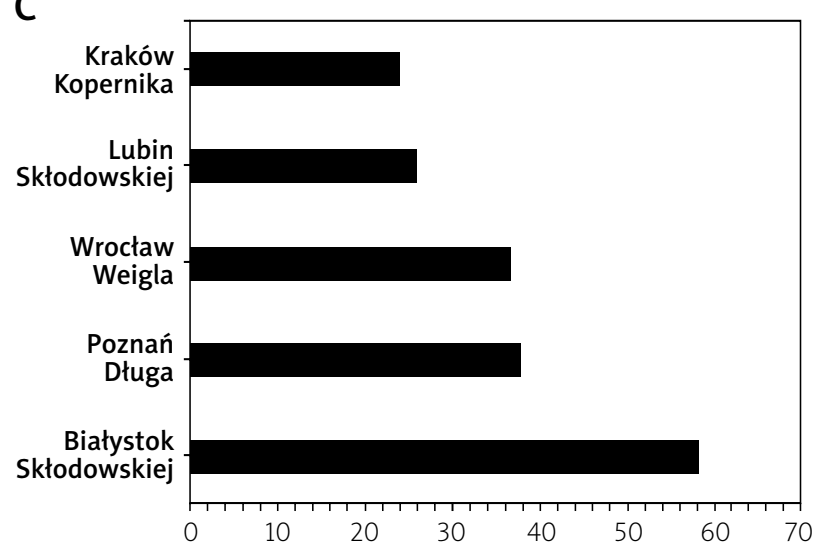

B

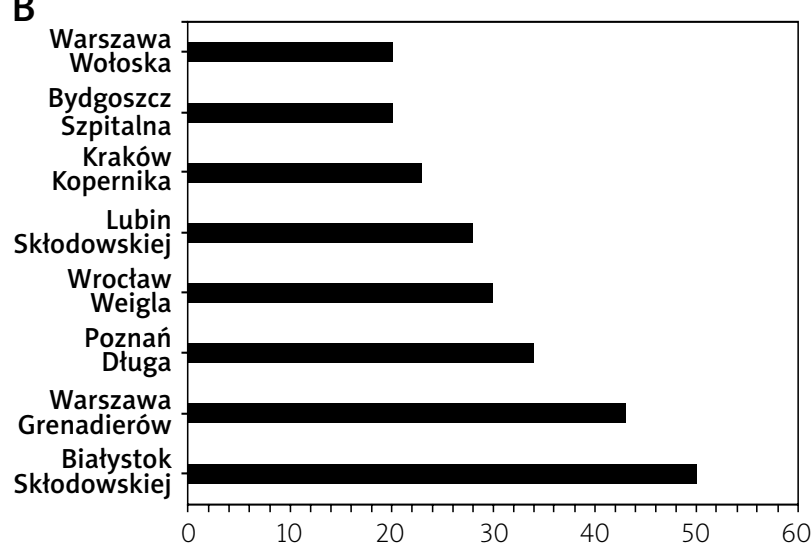

D

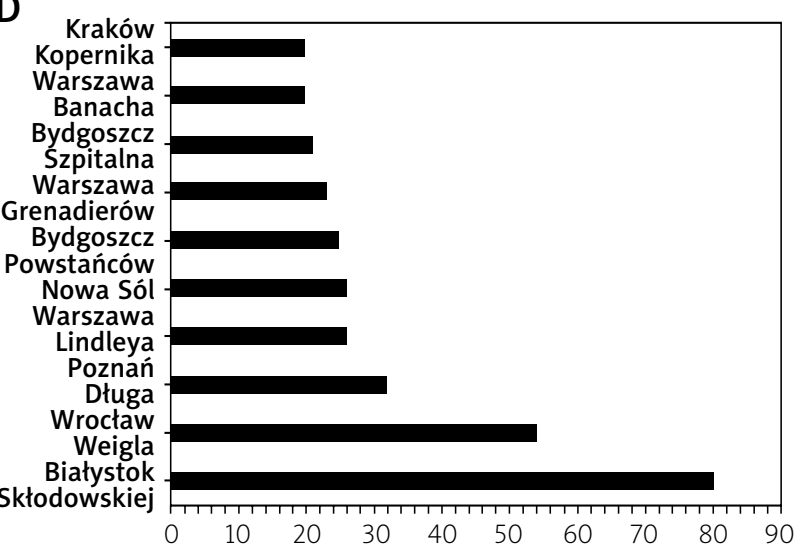

Figure 1. Number of catheterization laboratories in Poland with the rate of RA procedures more than 20 per year in 2014-2017: A - 2014, B - 2015, C - 2016, D - 2017 


\section{General characteristics}

The frequency of concomitant diseases in successive years did not differ significantly between particular years, with one exception for prior PCls. Their rate was higher in 2016 compared to others. Nonetheless, the frequency of concomitant diseases tends to decrease for diabetes, hypertension, prior coronary artery bypass grafting operation and cerebral stroke, smoking habits, and kidney failure, and also the mean age was lower in the most recent year (Table II).

\section{Clinical presentation, angiography and vascular} access

The percentage of patients with stable angina significantly increased from the year 2014 to 2017 (50.8\% vs. $63.1 \%, p<0.001)$, while the percentage of patients

Table II. General characteristics, clinical presentation, vascular access and angiographic image of patients treated with rotational atherectomy in Poland between 2014-2017

\begin{tabular}{|c|c|c|c|c|c|}
\hline \multirow[t]{2}{*}{ Variable } & \multicolumn{4}{|c|}{ Years } & \multirow[t]{2}{*}{$P$-value } \\
\hline & 2014 & 2015 & 2016 & 2017 & \\
\hline All percutaneous coronary interventions & 92,425 & 110,912 & 113,848 & 114,282 & $<0.001$ \\
\hline Rotational atherectomy & $181(0.19)$ & $458(0.41)$ & $536(0.47)$ & $698(0.61)$ & \\
\hline Age [years] & $72.3(10.4)$ & $71.8(9.5)$ & $71.5(9.6)$ & $71.4(9.7)$ & 0.85 \\
\hline Gender, male & $117(65.7)$ & $314(68.5)$ & $370(69)$ & $482(69)$ & 0.85 \\
\hline Diabetes & $63(34.8)$ & $154(33.6)$ & $184(34.3)$ & $218(31.3)$ & 0.62 \\
\hline Prior myocardial infarction & $84(46.4)$ & $225(49.1)$ & $277(51.7)$ & $338(48.4)$ & 0.56 \\
\hline Prior percutaneous coronary interventions & $90(49.7)$ & $245(53.5)$ & $339(63.2)$ & $359(51.4)$ & $<0.001$ \\
\hline Prior coronary artery bypass grafting & $31(17.1)$ & $66(14.4)$ & $84(15.7)$ & $88(12.6)$ & 0.3 \\
\hline Prior cerebral stroke & $10(5.5)$ & $21(4.6)$ & $20(3.7)$ & $30(4.3)$ & 0.76 \\
\hline Kidney failure & $25(13.8)$ & $56(12.2)$ & $54(10.1)$ & $81(11.6)$ & 0.48 \\
\hline Hypertension & $149(82.3)$ & $355(77.5)$ & $419(78.2)$ & $515(73.8)$ & 0.06 \\
\hline Chronic obstructive pulmonary disease & - & $12(2.62)$ & $18(3.3)$ & $18(2.57)$ & 0.67 \\
\hline Smoking & $34(18.8)$ & $57(12.4)$ & $83(15.5)$ & $104(14.9)$ & 0.21 \\
\hline \multicolumn{6}{|l|}{ Clinical presentation before $\mathrm{PCl}$ : } \\
\hline Stable angina & $92(50.8)$ & $185(41)$ & $360(67.4)$ & $441(63.3)$ & $<0.001$ \\
\hline Unstable angina & $62(34.2)$ & $71(15.7)$ & $123(23)$ & $177(25.4)$ & $<0.001$ \\
\hline NSTEMI & $17(9.4)$ & $69(15.3)$ & $43(8)$ & $62(8.9)$ & $<0.001$ \\
\hline STEMI & $10(5.5)$ & $126(27.9)$ & $8(1.5)$ & $16(2.3)$ & $<0.001$ \\
\hline \multicolumn{6}{|l|}{ Vascular access: } \\
\hline Femoral & $95(52.5)$ & $214(46.7)$ & $199(37.1)$ & $64(25.9)$ & $<0.001$ \\
\hline Radial left & $19(10.5)$ & $42(9.2)$ & $59(11)$ & $22(8.9)$ & 0.72 \\
\hline Radial right & $66(36.5)$ & $200(43.7)$ & $274(51.1)$ & $160(64.8)$ & $<0.001$ \\
\hline Other & $1(0.5)$ & $2(0.4)$ & $4(0.7)$ & $1(0.4)$ & 0.9 \\
\hline \multicolumn{6}{|l|}{ Angiographic image: } \\
\hline Single vessel disease & $64(35.3)$ & $65(34.9)$ & $74(38.5)$ & $85(34.4)$ & 0.82 \\
\hline MVD without LMCA involvement & $92(50.8)$ & $89(47.8)$ & $88(45.8)$ & $121(49)$ & 0.8 \\
\hline MVD with LMCA involvement & $24(13.2)$ & $30(17.2)$ & $29(15.1)$ & $41(16.6)$ & 0.8 \\
\hline Separate LMCA involvement & $1(0.5)$ & $2(1.1)$ & $1(0.5)$ & $0(0)$ & 0.83 \\
\hline
\end{tabular}

LMCA - left main coronary artery, MVD - multivessel disease, NSTEMI - non ST-segment elevation myocardial infarction, STEMI - ST-segment elevation myocardial infarction. 
with unstable angina (34.2\% vs. $25.4 \%, p<0.001)$, nonST segment elevation myocardial infarction (9.4\% vs. $8.9 \%, p<0.001)$ and ST segment elevation myocardial infarction $(5.5 \%$ vs. $2.3 \%, p<0.001)$ tended to decrease significantly. Similarly as in the general population of patients treated with $\mathrm{PCl}$, those with additional RA usage were significantly more often treated from right radial access in 2017 (64.8\%) compared to 2014 (36.5\%, $p$ < $0.001)$, while femoral access was rare $(52.5 \%$ vs. $25.9 \%$, $p<0.001)$. The angiographic image of patients qualified for PCI with RA did not change significantly in successive years (from 2014 to 2017), but a slight trend was noted regarding the increase in the percentage of patients with multivessel disease and left-main coronary artery involvement (from $13.2 \%$ in 2014 to $16.6 \%$ in 2017). This is presented in Table II.

\section{Procedural-related variables and culprit lesion characteristics}

In successive years (from 2014 to 2017), over 98\% of patients were treated with $\mathrm{PCl}$ and $\mathrm{RA}$ due to de-novo lesions. There were no patients with in-stent thrombosis. The rate of restenosis was comparable in successive years and ranged from $1.2 \%$ to $1.9 \%$. The mean contrast volume $(244.4 \pm 111.9 \mathrm{ml}$ vs. $208.9 \pm 96 \mathrm{ml}, p=0.0004)$ and radiation dose $(2.36 \pm 1.58$ Gy vs. $1.5 \pm 1.2 \mathrm{~Gy}, p<$ $0.001)$ significantly decreased in successive years from 2014 to 2017. Drug-eluting stents were implanted significantly more often in 2017 compared to 2014 (96.9\% vs. $99.7 \%, p<0.001)$, contrary to bare-metal stents, which were significantly less often used in 2017 (1.5\% vs. $0.2 \%$ ). Also, the frequency of intravascular ultrasound increased significantly in successive years from $3.9 \%$ in 2014 to $6.9 \%$ in 2017 ( $p=0.01$ ). This is presented in Table III.

\section{Angiographic effectiveness}

Angiographic effectiveness expressed as TIMI flow grade after $\mathrm{PCl}$ with RA did not change significantly in successive years. However, the percentage of patients with TIMI flow grade 3 was non-significantly lower in patients in 2017 compared to 2014 (95.3\% vs. 97.1\%); when combined with TIMI flow 2 (patent target artery) after $\mathrm{PCl}$, it reached over $98 \%$ each successive year from 2014 to 2017. It is also worth underlining that in successive years, from 2014 to 2017, there was a significant increase in the number of more advanced lesions, which was expressed as an increased rate of patients with TIMI 1 grade flow before $\mathrm{PCl}$ with RA $(9.7 \%$ vs. $19.7 \%, p=$ $0.005)$. This was parallel to the non-significant decrease of patients with TIMI 2 and 3 grade flow before $\mathrm{PCI}$ with RA. This is presented in Table III.

Similarly, after the division of the overall group according to the volume of RA performed in particular centers ( $<20$ RA per year $<$ ), there were no significant differences in procedural effectiveness or in the overall population in successive years. This is presented in Table IV.

\section{Periprocedural complications}

The overall complication rate decreased significantly from 2014 to 2017 (8.28\% vs. 3.29\%, $p=0.003$ ); however, in the last 3 years (2015-2017), it remained stable at around 3\%. Particular components of the overall complication rate did not change during the analyzed period, except for procedure-related cerebral stroke, which reached $1.65 \%$ in 2014 , while there were no cerebral strokes related to the RA procedure in successive years.

Similarly, after the division of the overall group according to the volume of RA performed in particular centers ( $<20$ RA per year $<$ ), there were no significant differences in procedure-related complication rates or in the overall population in successive years. However, the rate of periprocedural complications tended to be higher in low-volume centers in successive years and the overall population. Besides the fact that the overall complication rate tended to be higher in low-volume centers, the rate of coronary artery perforations was significantly higher in high-volume centers compared to low-volume ones $(p<0.05)$ regarding particular complications in the overall group of patients (Table $V$ ).

\section{Discussion}

The main finding of the current study is that the rate of $\mathrm{PCl}$ with RA increased more than three-fold in the last four years. This was accompanied by a simultaneous increase in the number of catheterization laboratories able to perform RA. The number of those centers increased more than two-fold. The increase in the number of catheterization laboratories was not accompanied by a decrease in the overall number of patients treated at high-volume centers with the annual rate of rotablations more than 10 or 20 procedures per year. It could be concluded that the increase in low-volume small centers able to perform rotablation was compensated by the parallel increase in the number of patients treated at high-volume centers. This indicates that the demand for rotational procedures in Poland is still greater than their supply, i.e. the current number of treatments performed. Based on those trends, it could be suspected that the results of rotablations would be poorer due to the fact that more patients are treated at less experienced centers. To reduce the possibility of such a phenomenon, a number of Proctor courses are held in Poland that maintain the performance of RA procedures at a high and acceptable level, despite the decentralization of their performance. In addition, a number of treatments at low-volume centers are performed under the supervision of operators from high-volume centers to maintain high quality rotablations. All of these activities contribute to the fact that both the frequency of complications and the effectiveness of the treatments es- 
Table III. Procedural indices, effectiveness of rotational atherectomy expressed as TIMI flow grade before and after $\mathrm{PCl}$ and procedure-related complications in patients treated with rotational atherectomy in Poland in the period 2014-2017

\begin{tabular}{|c|c|c|c|c|c|}
\hline \multirow[t]{2}{*}{ Variable } & \multicolumn{4}{|c|}{ Years } & \multirow[t]{2}{*}{$P$-value } \\
\hline & 2014 & 2015 & 2016 & 2017 & \\
\hline Contrast volume [ml] & $244.4(111.9)$ & $235.8(120.7)$ & $211.9(86.5)$ & $208.9(96)$ & 0.0004 \\
\hline Radiation dose [Gy] & $2.36(1.58)$ & $1.88(1.33)$ & $1.71(1.35)$ & $1.5(1.2)$ & $<0.001$ \\
\hline \multicolumn{6}{|l|}{ Type of culprit lesion: } \\
\hline De novo & $246(98.4)$ & $607 / 619(98.1)$ & $733(98.6)$ & $1,009(98.8)$ & 0.64 \\
\hline Restenosis & $4 / 250(1.6)$ & $12 / 619(1.9)$ & $10(1.3)$ & $12(1.2)$ & 0.64 \\
\hline In-stent thrombosis & $0(0)$ & $0(0)$ & $0(0)$ & $0(0)$ & - \\
\hline \multicolumn{6}{|l|}{ Type of intervention: } \\
\hline Drug-eluting stent & $251(96.9)$ & $583(97.2)$ & 707 (99.6) & $954(99.7)$ & $<0.001$ \\
\hline Bare-metal stent & $4 / 259(1.5)$ & $7 / 600(1.2)$ & $3 / 710(0.4)$ & 2/957 (0.2) & 0.02 \\
\hline Bioresorbable scaffold & $0(0)$ & $10 / 600(1.7)$ & $0(0)$ & $1 / 957(0.1)$ & $<0.001$ \\
\hline Drug-coated balloon & $5 / 181(2.7)$ & $9 / 458(2)$ & $8 / 536(1.5)$ & $4 / 698(0.6)$ & 0.07 \\
\hline Fractional flow reserve & $2(1.1)$ & $7(1.5)$ & $2(0.4)$ & $7(1)$ & 0.31 \\
\hline Intravascular ultrasound & $7(3.9)$ & $19(4.1)$ & $16(3)$ & $48(6.9)$ & 0.01 \\
\hline Optical coherence tomography & $1(0.55)$ & $9(2)$ & $0(0)$ & $3(0.4)$ & 0.0016 \\
\hline Bifurcation & 23/181 (12.7) & $44 / 458(9.6)$ & 64/536 (11.9) & 97/698 (13.9) & 0.17 \\
\hline Chronic total occlusion & 9/181 (5) & $19 / 458(4.1)$ & 26/536 (4.8) & $26 / 698(3.7)$ & 0.75 \\
\hline \multicolumn{6}{|l|}{ TIMI grade flow before $\mathrm{PCl}$ : } \\
\hline 0 & $14 / 175(8)$ & $33 / 441(7.5)$ & $39 / 524(7.4)$ & $44 / 676(6.5)$ & 0.86 \\
\hline 1 & $17 / 175(9.7)$ & $64 / 441(14.5)$ & 79/524 (15.1) & 133/676 (19.7) & 0.005 \\
\hline 2 & $49 / 175(28)$ & $110 / 441(24.9)$ & $107 / 524(20.4)$ & $154 / 676(22.8)$ & 0.14 \\
\hline 3 & 95/175 (54.3) & $234 / 441(53.1)$ & $299 / 524(57.1)$ & $345 / 676(51)$ & 0.22 \\
\hline \multicolumn{6}{|l|}{ TIMI grade flow after PCI: } \\
\hline 0 & $0 / 176(0)$ & $2 / 448(0.4)$ & $4 / 527(0.7)$ & $3 / 685(0.4)$ & 0.63 \\
\hline 1 & $1 / 176(0.6)$ & $4 / 448(0.9)$ & $1 / 527(0.2)$ & $4 / 685(0.6)$ & 0.52 \\
\hline 2 & $4 / 176(2.3)$ & $7 / 448(1.6)$ & $11 / 527(2.1)$ & $25 / 685(3.6)$ & 0.13 \\
\hline 3 & $171 / 176(97.1)$ & $435 / 448(97.1)$ & $511 / 527(97)$ & $653 / 685(95.3)$ & 0.29 \\
\hline \multicolumn{6}{|l|}{ Procedure-related complications: } \\
\hline All complications & $15(8.28)$ & $12(2.62)$ & $16(2.98)$ & $23(3.29)$ & 0.003 \\
\hline Coronary artery perforation & $3(1.65)$ & $4(0.87)$ & $5(0.93)$ & $6(0.85)$ & 0.79 \\
\hline Death & $1(0.55)$ & $0(0)$ & $0(0)$ & $1(0.14)$ & 0.2 \\
\hline Cerebral stroke & $3(1.65)$ & $0(0)$ & $0(0)$ & $0(0)$ & 0.01 \\
\hline No-reflow phenomenon & $2(1.1)$ & $2(0.43)$ & $4(0.74)$ & $2(0.28)$ & 0.48 \\
\hline Myocardial infarction & $1(0.55)$ & $0(0)$ & $1(0.18)$ & $3(0.42)$ & 0.45 \\
\hline Arterial dissection & $1(0.55)$ & $1(0.53)$ & $0(0)$ & $1(0.4)$ & 0.79 \\
\hline Cardiac arrest & $3(1.65)$ & $4(0.87)$ & $2(0.37)$ & $6(0.85)$ & 0.39 \\
\hline Bleeding & $0(0)$ & $1(0.21)$ & $2(0.37)$ & $3(0.42)$ & 0.79 \\
\hline Allergic reaction & $0(0)$ & $0(0)$ & $2(0.37)$ & $1(0.14)$ & 0.46 \\
\hline
\end{tabular}

$\mathrm{PCl}$ - percutaneous coronary intervention, TIMI - thrombolysis in myocardial infarction. 
Table IV. Effectiveness of rotational atherectomy expressed as TIMI flow grade before and after PCI in Poland during 2014-2017 according to the number of RA procedures performed annually

\begin{tabular}{|c|c|c|c|c|c|c|c|c|c|c|}
\hline \multirow{3}{*}{$\begin{array}{l}\text { TIMI } \\
\text { grade } \\
\text { flow }\end{array}$} & \multicolumn{10}{|c|}{ Number of RA procedures performed per year per catheterization laboratory } \\
\hline & \multicolumn{2}{|c|}{2014} & \multicolumn{2}{|c|}{2015} & \multicolumn{2}{|c|}{2016} & \multicolumn{2}{|c|}{2017} & \multicolumn{2}{|c|}{ 2014-2017 } \\
\hline & $<20$ & $>20$ & $<20$ & $>20$ & $<20$ & $>20$ & $<20$ & $>20$ & $<20$ & $>20$ \\
\hline \multicolumn{11}{|c|}{ Before PCl: } \\
\hline 0 & $6(7.2)$ & $8(8.7)$ & $19(9.4)$ & $14(5.8)$ & $22(6.4)$ & $17(9.3)$ & $28(7.5)$ & $16(4.9)$ & $75(7.5)$ & $55(6.7)$ \\
\hline 1 & $7(8.4)$ & $10(10.9)$ & 30 (14.8) & $34(14.2)$ & $63(18.4)$ & $16(8.8)^{\star}$ & $78(21)$ & 55 (18) & $178(17.8)$ & $115(14)^{*}$ \\
\hline 2 & $27(32.5)$ & $22(23.9)$ & $49(22.1)$ & $61(25.2)$ & $62(18.1)$ & $45(24.7)$ & $82(22.1)$ & $72(23.6)$ & $220(22)$ & $200(24.4)$ \\
\hline 3 & $43(51.8)$ & $52(56.5)$ & $104(51.5)$ & $130(55.2)$ & $195(57)$ & $104(57.1)$ & $183(49.3)$ & $162(53.1)$ & $525(52.6)$ & $448(54.8)$ \\
\hline \multicolumn{11}{|c|}{ After PCI: } \\
\hline 0 & $0(0)$ & $0(0)$ & $1(0.5)$ & $1(0.4)$ & $1(0.3)$ & $3(1.6)$ & $2(0.5)$ & $1(0.3)$ & $4(0.4)$ & $5(0.6)$ \\
\hline 1 & $1(1.2)$ & $0(0)$ & $1(0.5)$ & $3(1.2)$ & $1(0.3)$ & $0(0)$ & $2(0.5)$ & $2(0.6)$ & $5(0.5)$ & $5(0.6)$ \\
\hline 2 & $3(3.6)$ & $1(1.1)$ & $5(2.5)$ & $2(0.8)$ & $9(2.6)$ & $2(1.1)$ & $14(3.8)$ & $11(3.5)$ & $31(3.1)$ & $16(1.9)$ \\
\hline 3 & 80 (95.2) & 91 (98.9) & 194 (96.5) & 241 (97.6) & 334 (96.8) & 177 (97.2) & 352 (95.1) & 301 (95.5) & 960 (96) & 810 (96.9) \\
\hline
\end{tabular}

${ }^{*} p<0.05$ comparing the difference between centers with $>$ and $<$ than 20 RA procedures per year; $P C I-$ percutaneous coronary intervention, $R A-$ rotational atherectomy, TIMI - thrombolysis in myocardial infarction.

Table V. Procedure-related complications in patients treated with rotational atherectomy in Poland during 2014-2017 according to the number of RA procedures performed annually

\begin{tabular}{lcccccccccc} 
& \multicolumn{7}{c}{ Number of RA procedures performed per year per catheterization laboratory } \\
\cline { 2 - 11 } & \multicolumn{2}{c}{2014} & \multicolumn{2}{c}{2015} & \multicolumn{2}{c}{2016} & 2017 & $2014-2017$ \\
\cline { 2 - 11 } & $<20$ & $>20$ & $<20$ & $>20$ & $<20$ & $>20$ & $<20$ & $>20$ & $<20$ & $>20$ \\
\hline All complications & $8(9.1)$ & $7(7.5)$ & $5(2.4)$ & $7(2.8)$ & $11(3.1)$ & $5(2.7)$ & $14(3.8)$ & $9(2.7)$ & $38(3.7)$ & $28(3.3)$ \\
\hline CAP & $0(0)$ & $3(3.2)$ & $1(0.5)$ & $3(1.2)$ & $2(0.6)$ & $3(1.6)$ & $2(0.5)$ & $4(1.2)$ & $5(0.5)$ & $13(1.5)^{\star}$ \\
\hline Death & $1(1.1)$ & $1(1)$ & $0(0)$ & $0(0)$ & $0(0)$ & $0(0)$ & $1(0.3)$ & $0(0)$ & $2(0.2)$ & $1(0.1)$ \\
\hline Cerebral stroke & $3(3.4)$ & $0(0)$ & $0(0)$ & $0(0)$ & $0(0)$ & $0(0)$ & $0(0)$ & $0(0)$ & $3(0.8)$ & $0(0)$ \\
\hline No-reflow & $1(1.1)$ & $1(1.1)$ & $2(0.9)$ & $0(0)$ & $3(0.8)$ & $1(0.5)$ & $1(0.3)$ & $1(0.3)$ & $7(0.7)$ & $3(0.3)$ \\
\hline Ml & $1(1.1)$ & $0(0)$ & $0(0)$ & $0(0)$ & $1(0.3)$ & $0(0)$ & $1(0.3)$ & $2(0.6)$ & $3(0.3)$ & $2(0.2)$ \\
\hline Arterial dissection & $1(1.1)$ & $0(0)$ & $1(1.6)$ & $0(0)$ & $0(0)$ & $0(0)$ & $1(0.9)$ & $0(0)$ & $3(0.8)$ & $0(0)$ \\
\hline Cardiac arrest & $1(1.1)$ & $2(2.1)$ & $1(0.5)$ & $3(1.2)$ & $1(0.3)$ & $1(0.5)$ & $5(1.3)$ & $1(0.3)$ & $8(0.8)$ & $7(0.82)$ \\
\hline Bleeding & $0(0)$ & $0(0)$ & $0(0)$ & $1(0.4)$ & $2(0.6)$ & $0(0)$ & $2(0.5)$ & $1(0.3)$ & $4(0.4)$ & $2(0.2)$ \\
\hline Allergic reaction & $0(0)$ & $0(0)$ & $0(0)$ & $0(0)$ & $2(0.6)$ & $0(0)$ & $1(0.3)$ & $0(0)$ & $3(0.3)$ & $0(0)$
\end{tabular}

${ }^{*} P<0.05$ comparing the difference between centers with $>$ and $<$ than 20 RA procedures per year. CAP - coronary artery perforation, MI - myocardial infarction, $R A$ - rotational atherectomy.

timated as the patency of the vessel after the procedure are maintained at a stable level.

Based on the current analysis, patients qualified for $\mathrm{PCl}$ with RA presented more complicated lesions including left-main coronary artery involvement in multi-vessel disease in successive years, but on the other hand, there were more patients with stable angina before the procedure in more recent years. Thus, it may be concluded that preparation for the procedure was better.
However, a number of recently published papers encourage operators to use rotablation more frequently in acute coronary syndromes [9]. The procedure effectiveness assessed as target artery patency did not decrease in the most recent years, even though target arteries had poorer TIMI grade flow before the procedure in recent years. While the dissemination and progression of coronary artery atherosclerosis of patients qualified for $\mathrm{PCl}$ with RA tended to be greater, the rate of concom- 
itant diseases and the mean age tended to decrease. This could suggest that among sick patients, those less ill have been treated in the most recent years within the aspect of the general clinical state, while concerning coronary atherosclerosis, patients treated with RA tend to present more advanced coronary atherosclerosis. Moreover, it has to be mentioned that remaining in line with current trends, femoral, instead of radial access, has become a minority. This was also indicated in one of the previously published papers analyzing Polish patients treated with RA and other reports $[10,11]$ was and was also not reflected in the increased rate of procedure-related complications, which was stable in the last 3 years of the present analysis and was around 3\%. It should be noted that most of the previously published registers concerned significantly smaller groups of patients, and their analysis included complications from the entire hospitalization period and not only from the stay in the catheterization room. That is why their percentages were higher compared to our study [12, 13]. However, one may have reservations about the low frequency and underestimation of the number of procedure-related complications, but in the case of analysis among large groups of patients, it is assumed that certain trends do not change significantly and reflect real life [14].

\section{Limitations}

This study was based on a nationwide volunteer registry rather than a prospective randomized clinical trial. This tends to decrease and underestimate the detection of periprocedural complication rates and other crucial variables which are dependent on subjective assessment of the operator, despite the large overall interventional volume included in our analysis. Also, the assessment of blood flow in the target artery using the TIMI scale is subjective and depends on individual operators, despite the fact that a large number of procedures can significantly reduce this effect. Furthermore, the current analysis does not include all in-hospital complications, which certainly weakens its value. The low percentage of myocardial infarctions is particularly noteworthy. Nonetheless, the advantage of the current study is that the results are closer to real life than to randomized clinical trials and show clinical data depicting the results of rotational atherectomy in Poland as one of the leaders in Central Europe.

\section{Conclusions}

The current trends and procedural outcomes of $\mathrm{PCl}$ with RA are promising. The substantial increase in the number of low-volume centers and patients treated at them is compensated by the increase in the number of patients at high-volume centers. Continuous substantive supervision and permanent training contribute to maintaining a high level of rotablation. Those fluctuations in the location of RA treatment are not related to poorer pro- cedural outcomes or an increased rate of procedure-related complications. Shortening the time of surgery, the greater frequency of radial access and reducing the dose of contrast also contribute to lessening the percentage of procedure-related complications. Such a rapid increase in the number of treatments and centers performing them indicate very high market demand for rotablation.

\section{Conflict of interest}

The authors declare no conflict of interest.

\section{References}

1. Kini A, Marmur JD, Duvvuri S, et al. Rotational atherectomy: improved procedural outcome with evolution of technique and equipment. Single-center results of first 1,000 patients. Catheter Cardiovasc Interv 1999; 46: 305-11.

2. Abdel-Wahab M, Richardt G, Büttner JH, et al. High-speed rotational atherectomy before paclitaxel-eluting stent implantation in complex calcified coronary lesions: the randomized ROTAXUS (Rotational Atherectomy Prior to Taxus Stent Treatment for Complex Native Coronary Artery Disease) trial. JACC Cardiovasc Interv 2013; 6: 10-9.

3. Januszek R, Siudak Z, Dziewierz A, et al. Predictors of in-hospital effectiveness and complications of rotational atherectomy (from the ORPKI Polish National Registry 2014-2016). Catheter Cardiovasc Interv 2018; 92: E278-7.

4. Barbato E, Carrié D, Dardas P, et al.; European Association of Percutaneous Cardiovascular Interventions. European expert consensus on rotational atherectomy. Eurolntervention 2015; 11: 30-6.

5. Januszek R, Siudak Z, Dziewierz A, et al. Chronic obstructive pulmonary disease affects the angiographic presentation and outcomes of patients with coronary artery disease treated with percutaneous coronary interventions. Pol Arch Intern Med 2018; 128: 24-34

6. Januszek R, Dziewierz A, Siudak Z, et al. Predictors of periprocedural complications in patients undergoing percutaneous coronary interventions within coronary bypass grafts. Cardiol J 2018; DOI: $10.5603 /$ CJ.a2018.0044.

7. Januszek RA, Dziewierz A, Siudak Z, et al. Diabetes and periprocedural outcomes in patients treated with rotablation during percutaneous coronary interventions. Cardiol J 2018; doi: 10.5603/CJ.a2018.0102.

8. Thygesen K, Alpert JS, Jaffe AS, et al. Third universal definition of myocardial infarction. Eur Heart J 2012; 33: 2551-67.

9. Kübler P, Zimoch W, Kosowski M, et al. Acute coronary syndrome - still a valid contraindication to perform rotational atherectomy? Early and one-year outcomes. J Cardiol 2018; 71: 382-8.

10. Kübler P, Zimoch W, Kosowski M, et al. In patients undergoing percutaneous coronary intervention with rotational atherectomy radial access is safer and as efficient as femoral access. J Interv Cardiol 2018; 31: 471-7.

11. Gioia GD, Morisco C, Barbato E. Severely calcified coronary stenoses: novel challenges, old remedy. Adv Interv Cardiol 2018; 14: 115-6.

12. Gorol J, Tajstra M, Hudzik B, et al. Comparison of outcomes in patients undergoing rotational atherectomy after unsuccessful coronary angioplasty versus elective rotational atherectomy. Adv Interv Cardiol 2018; 14: 128-34. 
13. Iannaccone M, Piazza F, Boccuzzi GG, et al. ROTational AThErectomy in acute coronary syndrome: early and midterm outcomes from a multicentre registry. Eurolntervention 2016; 12: 1457-64.

14. Januszek R, Siudak Z, Dziewierz A, et al. Bailout rotational atherectomy in patients with myocardial infarction is not associated with an increased periprocedural complication rate or poorer angiographic outcomes in comparison to elective procedures (from the ORPKI Polish National Registry 2015-2016). Adv Interv Cardiol 2018; 14: 135-43. 